This is the peer reviewed version of the following article: "Pérez, Y., Gómara, M.J., Yuste, E., Gómez, P., Pérez, J.J. and Haro, I. (2017) Structural study of a new HIV-1 entry inhibitor and interaction with the HIV-1 fusion peptide in dodecylphosphocholine micelles, (23), 11703-11713." which has been published in final form at [doi: 10.1002/chem.201702531]. This article may be used for non-commercial purposes in accordance with Wiley Terms and Conditions for Self-Archiving." 


\section{Structural study of a new HIV-1 entry inhibitor and interaction with the HIV-1 fusion peptide in dodecylphosphocholine micelles}

Yolanda Pérez, ${ }^{[b]}$ Maria José Gómara ${ }^{[a]}$, Eloisa Yuste ${ }^{[c], \#}$, Patricia Gomez-Gutierrez ${ }^{[\mathrm{d}]}$, Juan Jesús Pérez ${ }^{[\mathrm{d}]}$ and Isabel Haro ${ }^{*[\mathrm{a}]}$

Abstract: Abstract Text, $800-1000$ characters.

\section{Introduction}

Antiviral agents that block HIV-1 entry (entry inhibitors) are considered as an effective class of drugs and have been increasingly exploited in recent years. ${ }^{1-5}$ At present, only two of

them-members of this class have been clinically approved: Enfuvirtide (T20), ${ }^{6}$ a 36 -mer water soluble peptide derived from the C-terminal heptad repeat region of gp41 and Maraviroc (MVC), ${ }^{7}$ which binds to the CCR5 co-receptor and inhibits HIV-1 entry by blocking the gp120-CCR5 interaction. In addition, only VIRIP (VIRus-Inhibitory Peptide, natural peptide identified in human serum) has been reported to bind to the highly conserved hydrophobic gp41 fusion peptide of HIV-1 (FP23)

[a] Dr. M.J. Gómara and Dr. L Haro Unit of Synthesis and Biomedical Applications of Peptides IQAC-CSIC

Jordi Girona, 18-26, 08034, Barcelona, Spai

[b] Dr. Y. Pérez Nuclear Magnetic Resonance Facility IQAC-CSIC

Jordi Girona, 18-26, 08034, Barcelona, Spain

[c] P. Gomez-Gutierrez and Prof. J.J.Pérez

Department of Chemical Engineering (ETSEIB). Universitat Politecnica de Catalunya. Barcelona, Spain

[d] Dr. E. Yuste

AIDS Research Unit, Hospital Clínic, Barcelona, Spain

\# Present address: AIDS Immunopathology Unit, Centro Nacional Microbiología, Instituto de Salud Carlos III, Madrid, Spain

*To whom correspondence should be addressed.

E-mail: Isabel.haro@iqac.csic.es

Supporting information for this article can be found under http://dx.doi.org/...... preventing its insertion into the host cell membrane . $^{8,9}$

Previous studies support the hypothesis that the $G B$ virus $C$ (GBV-C) E1 protein interferes HIV-1 entry, being consequently considered as an attractive model peptide for the development of novel anti-HIV therapies. ${ }^{10}$ Particularly, our group has defined a new peptide lead, derived from the region (139-156) of the E1 protein, as a HIV-1 entry inhibitor. This 18-mer synthetic peptide, namely E1P47, has demonstrated a broad spectrum of activity against HIV-1. Moreover, biochemical and biophysical assays such as a competitive ELISA using specific gp41-targeting mAbs fluorescence resonance energy transfer as well as haemolysis assays have demonstrated that this $\mathrm{E} 1$ peptide sequence interacts with FP23. ${ }^{11}$ To get further insight into the features of E1P47 peptide inhibition mechanism it is necessary to understand the conformational profile of the inhibitor, how it inhibits HIV-1 entry (the binding mode) and to have structureactivity information to identify the relevant structural elements for the E1P47 activity. Thus, specific information at atomic resolution on E1P47 structure and the nature on the peptidepeptide (E1P47-FP23) interactions obtained by Nuclear Magnetic Resonance (NMR) could lead to the characterization of the inhibition mechanism.

There are a large number of studies about the structure of FP23 and its conformational changes associated to membrane fusion ${ }^{12-15}$. One of the requirements for these studies is to do the measurements in conditions that mimics the membrane environment. Thus, it has been observed that the FP23 adopts different conformations that can be related to its physiological activity, depending on conditions such as the peptide-to-lipid molar ratio, membrane lipid composition (per example, the presence of cholesterol), the concentration of divalent cations, the $\mathrm{pH}$ and the amino acid sequence studied. ${ }^{16-20}$ Although, the use of dodecylphosphocholine (DPC) micelles for the 
determination of peptide/protein structure in membrane environments by NMR spectroscopy was first described by Wüthrich and co-workers in early 80 's, ${ }^{21}$ there are few previously reported works which study by NMR the interaction between two peptides in lipid environment. ${ }^{22,23}$

In this work, we focus on the characterization of E1P47 structural features which are determinant for its biological activity and the study of the interaction of E1P47 peptide with the proposed FP23 viral target. Specifically, we report the structure of E1P47 peptide determined by NMR spectroscopy in DPC micelles solved using restrained molecular dynamics calculations. In parallel, by screening a library composed by 49 variants of E1P47 peptide (both positional alanine scanning and truncated forms), we have studied the structure-activity relationship. Last, the acquisition of different NMR experiments in DPC micelles (peptide-peptide titration, diffusion NMR and addition of paramagnetic relaxation agents) allows the proposal of an inhibition mechanism for E1P47 peptide through interaction with FP23 at membrane level. Our data support the hypothesis that a peptide from non-pathogenic E1 GBV-C protein, with a helix-turn-helix structure, inhibits HIV-1 fusion by binding to FP23 peptide.

\section{Results and Discussion}

\section{Antiviral effect of E1P47 related peptides}

To characterize the E1P47 peptide sequence features that could be related with its anti-HIV-1 activity a structure-activity study has been carried out. The previously obtained E1P47 analogues with restricted conformations demonstrated a loss of activity. Thus, disulphide cyclic as well as head-to-tail cyclic E1P47 analogues were significantly less active than the linear peptide indicating that the addition of a constraint to the peptide sequence by means of a cyclic formation led to a fixed conformation that did not seem to fit the active site properly. ${ }^{10}$ In order to investigate the structural features that determine the activity of E1P47 peptide, truncated analogues from 17 to 8 amino acid residues mapping the $\mathrm{N}$ - and $\mathrm{C}$-terminus as well as the core of the primary sequence were synthesized on solid phase (Table S1, Supporting Information) and tested on HIV-1 NL4-3 replication cellular assays (Materials and Methods in Supporting Information). Table 1 shows the primary sequence of the truncated peptides, their antiviral activities expressed as IC50 values and the highest not toxic concentrations. Most of the shorter peptides did not demonstrated anti-HIV-1 activity in the low micromolar range. The reduction of two residues either on $\mathrm{N}$ - or on $\mathrm{C}$ - terminus decreased the antiviral activity of the parent peptide sequence, which indicates that the shorter amino acid sequence that maintains the antiviral activity is almost the former 18-mer peptide.

Besides, an alanine positional scanning was carried out to identify the amino acid residues that have a significant contribution to the antiviral activity and therefore might be involved in the interaction with the HIV-1 fusion peptide. Table 2 shows the primary structure of the 18-mer analogues, their anti-
HIV activities and toxicities. These results demonstrated that the six N-terminal amino acids are essential for maintaining the antiviral activity since the substitution of each one by Ala determines the loss of activity. Moreover, the Pro and the Asp residues of the core region also contribute decisively to the antiHIV-1 activity. The substitution of the remaining positions by Ala did not dramatically change the activity of the peptide. Moreover, the synthesized scrambled peptide of E1P47 did not demonstrate any antiviral activity.

Table 1. Inhibitory activity on HIV-1 NL4-3 infectivity assay of E1P47 truncated peptides.

\begin{tabular}{rll}
\hline Primary sequence & $\begin{array}{c}\mathrm{IC}_{50} \\
(\mu \mathrm{M})\end{array}$ & $\begin{array}{c}\text { Toxicity } \\
(\mu \mathrm{M})\end{array}$ \\
\hline WILEYLWKVPFDFWRGVI & 5 & $>60$ \\
\hline N-truncated analogues & & \\
\hline ILEYLWKVPFDFWRGVI & 5 & $>100$ \\
LEYLWKVPFDFWRGVI & 20 & $>100$ \\
EYLWKVPFDFWRGVI & 50 & $>100$ \\
YLWKVPFDFWRGVI & 50 & $>100$ \\
LWKVPFDFWRGVI & 20 & $>100$ \\
WKVPFDFWRGVI & - & $>100$ \\
KVPFDFWRGVI & - & $>100$ \\
VPFDFWRGVI & - & $>100$ \\
PFDFWRGVI & - & $>100$ \\
FDFWRGVI & - & $>100$
\end{tabular}

Core-truncated analogues

$\begin{array}{lll}\text { PFDFWRGV } & - & \\ \text { VPFDFWRG } & - & >60\end{array}$

$\begin{array}{lll}\text { VPFDFWRG } & - & >60 \\ \text { KVPFDFWR } & - & >60\end{array}$

WKVPFDFW $>60$

LWKVPFDF

YLWKVPFD

EYLWKVPF $\quad-\quad>60$

LEYLWKVP

ILEYLWKV $\quad-\quad>60$

C-truncated analogues

\begin{tabular}{lll}
\hline WILEYLWK & - & $>60$ \\
WILEYLWKV & - & $>30$ \\
WILEYLWKVP & - & $>60$ \\
WILEYLWKVPF & - & $>60$ \\
WILEYLWKVPFD & - & $>60$ \\
WILEYLWKVPFDF & - & $>60$ \\
WILEYLWKVPFDFW & - & $>60$ \\
WILEYLWKVPFDFWR & 10 & \\
WILEYLWKVPFDFWRG & 25 & \\
WILEYLWKVPFDFWRGV & 10 & \\
\hline
\end{tabular}


Table 2. Inhibitory activity on HIV-1 NL4-3 infectivity assay of E1P47 alanine analogues.

\begin{tabular}{lcc}
\hline Primary sequence & $\mathrm{IC}_{50}(\mu \mathrm{M})$ & $\begin{array}{l}\text { Toxicity } \\
(\mu \mathrm{M})\end{array}$ \\
\hline Alanine Positional Scanning & 5 & $>60$ \\
\hline WILEYLWKVPFDFWRGVI & 5 & $>60$ \\
WILEYLWKVPFDFWRGVA & 10 & $>60$ \\
WILEYLWKVPFDFWRGAI & 5 & $>10$ \\
WILEYLWKVPFDFWRAVI & 10 & \\
WILEYLWKVPFDFWAGVI & 10 & $>100$ \\
WILEYLWKVPFDFARGVI & 10 & $>100$ \\
WILEYLWKVPFDAWRGVI & - & $>20$ \\
WILEYLWKVPFAFWRGVI & 5 & $>10$ \\
WILEYLWKVPADFWRGVI & - & $>10$ \\
WILEYLWKVAFDFWRGVI & 10 & $>100$ \\
WILEYLWKAPFDFWRGVI & 20 & $>50$ \\
WILEYLWAVPFDFWRGVI & 20 & $>50$ \\
WILEYLAKVPFDFWRGVI & - & $>50$ \\
WILEYAWKVPFDFWRGVI & - & $>50$ \\
WILEALWKVPFDFWRGVI & - & $>50$ \\
WILAYLWKVPFDFWRGVI & - & $>50$ \\
WIAEYLWKVPFDFWRGVI & - & $>50$ \\
WALEYLWKVPFDFWRGVI & - & $>50$ \\
AILEYLWKVPFDFWRGVI & & $>50$ \\
\hline Scrambled Peptide (SCR) & - & \\
\hline ELDIRLKGFFVWIVWPWY & & \\
\hline
\end{tabular}

E1P47 NMR chemical shift assignment in DPC micelles

There is very little information about GBV-C E1 envelope glycoprotein structure. ${ }^{24}$ It seems that GBV-C E1 protein presents some hydrophobic regions suggestive of transmembrane domains (predicted by TMHMM Server v. 2.0, Figure 1a), but studies examining the structure of human GBV-C E1 proteins by NMR, Cryo-Electron Microscopy and/or X-Ray diffraction have not been performed. Our preliminary NMR studies with E1P47 peptide in aqueous solution revealed a 1Dproton spectrum with small and broadened resonances, indicative of extensive aggregation, confirming that some regions of GBV-C envelope $\mathrm{E} 1$ protein and some of its derivative peptides should be soluble in a membrane environment. Analysis of GBV-C E1 glycoprotein transmembrane topology using the TMHMM online server seems to indicate that residues 1-80 and 172-190 are presented outside while residues 81-103 and $149-171$ are located at the transmembrane region, and residues 104-148 are inside (Figure 1a), so the predicted location for E1P47 is proximal and/or inside the membrane region. Taking into account this information and the amino acid composition of E1P47 (two positive and two negative charged residues at neutral $\mathrm{pH}$ ), deuterated dodecylphosphocholine (DPC-d38) with a zwitterionic head group similar to that of phosphatidylcholine was used as eukaryotic membrane mimetic system to perform the subsequent NMR studies. ${ }^{25,26}$ Due to the high hydrophobicity of E1P47, a DPC-d38 concentration high enough to allow dissolving the peptide without the observation of macroscopic precipitation was used. The effect of DPC concentration was evaluated acquiring $1 \mathrm{D}{ }^{1} \mathrm{H}$ NMR spectra of 1 $\mathrm{mM}$ E1P47 peptide complexed with DPC at three lipid concentrations (50, 100 and $150 \mathrm{mM}$ ), observing small chemical shift changes and good solubility in this range of DPC concentrations (Figure S1, Supplementary Information). E1P47 resonance assignment is difficult due to overlapping and broadening of several peaks in presence of DPC. To make it easier and to confirm that the NOEs cross-peaks are correctly assigned, we decided to prepare three tryptophan to alanine mutants, one for every tryptophan in the E1P47 sequence (W139A (Trp-1), W145A (Trp-7) and W152A (Trp-14)). As the indole $\mathrm{NH}$ protons resonate in a well-resolved, non-overlapping low-field region of the spectrum, is easy to assign and characterize their NOEs cross peaks to neighbouring residues. Comparing the ${ }^{1} \mathrm{H} 1 \mathrm{D}$ and ${ }^{1} \mathrm{H}-{ }^{1} \mathrm{H}$ 2D NMR spectra of the three mutants and the parent peptide in DPC aqueous solution (Figure S2, Supplementary Information), we could initially assign unambiguously the three $\mathrm{NH}$ and aromatic indole protons and to use these assignments as starting point to identify the rest of amino acids (Figures $1 \mathrm{~b}$ and $1 \mathrm{c}$ ). The signals attributable to the Trp-7 and Trp-14 indole NH protons undergo large upfield shifts (Figure 1c) when comparing E1P47 dissolved in DMSO to E1P47 in DPC micelles, possibly due to the important conformational change after peptide insertion in DPC micelles, like changes in the existence and/or nature of the hydrogen bonds involving these protons. To assign E1P47 peptide in DPC micelles (Figure 1d), 2D ${ }^{1} \mathrm{H}-{ }^{1} \mathrm{H}$ NMR spectra were acquired using a sample with detergent/peptide molar ratio $\sim 100$ at $308 \mathrm{~K}$ and the assignment was done following the standard sequentia assignment procedure (Table S2 and Materials and Methods in Supplementary Information). Moreover, due to the presence of severe overlapping in the aromatic region of $2 \mathrm{D}{ }^{1} \mathrm{H},{ }^{1} \mathrm{H}$ spectra, we confirmed the assignment of Phe/Tyr/Trp aromatic protons by the acquisition of supplementary heteronuclear $2 \mathrm{D}{ }^{1} \mathrm{H}-{ }^{13} \mathrm{C}$ HSQC and HSQC-TOCSY experiments (Figure S3, Supplementary Information). This allowed the unambiguous assignment of aromatic side chain proton resonances due to the improvement in resolution obtained by using the ${ }^{13} \mathrm{C}$ dimension.

\section{E1P47 acquires a helix-turn-helix motive in DPC micelles}

Identification of the peptide secondary structure involves analysis of characteristic patterns of NOE/ROE cross-peaks (Figure S4, Supplementary Information). Table S3 (Supplementary Information) summarizes the sequential and medium-range NOE cross peaks Observed for the E1P47 peptide. However, the presence (or absence) of several crosspeaks could not be assessed unambiguously due to spectral overlap. At the E1P47 $\mathrm{N}$-terminus, sequential and several medium-range NOE cross-peaks, indicative of a $\alpha$-helical conformation could be assigned between Trp-1 and Lys-8. In addition, several 3-amino acid NOEs $\alpha \mathrm{N}(\mathrm{i}, \mathrm{i}+3), \mathrm{N}, \mathrm{N}(\mathrm{i}, \mathrm{i}+3)$ and $\alpha \beta(i, i+3)$ could also be assigned to this segment, reinforcing the adoption of a $\alpha$-helix conformation. Obvious breaks of $(\mathrm{i}, \mathrm{i}+3)$ NOEs between Trp-7/Pro-10 suggest interruption of helix from Lys-8 to Val-9 or Pro-10. Although, Lys-8 and Val-9 NOE 
correlations are difficult to evaluate due to overlapping with aromatic resonances.

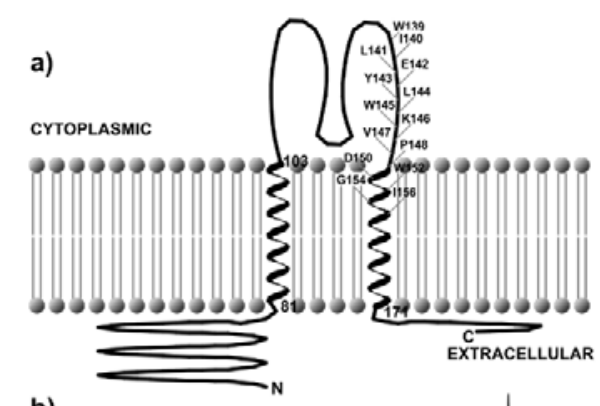

b)

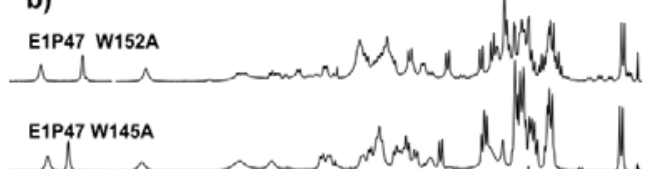

c)

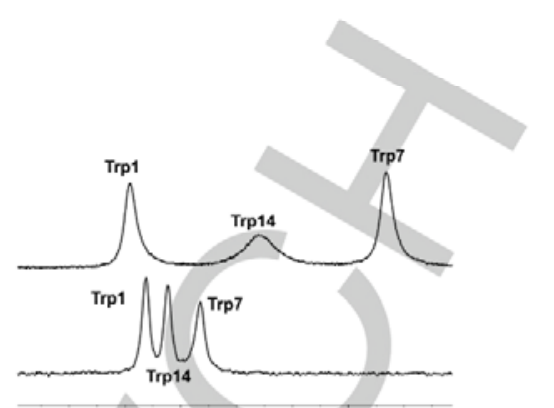

d)
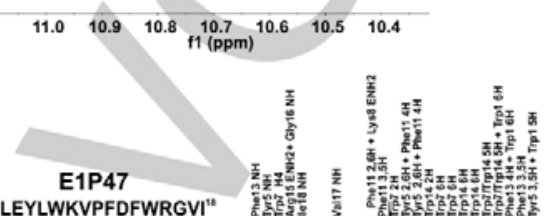

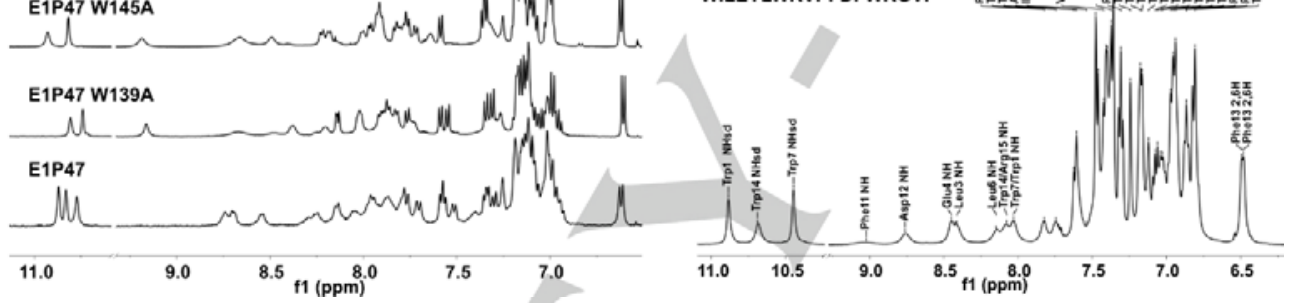

Figure 1. NMR spectra of E1P47 and its mutants in DMSO and DPC micelles. (a) Representation (using TMPres2D tool, http://bioinformatics.biol.uoa.gr/TMRPres2D/) of transmembrane regions of GBV-C E1 protein predicted by TMHMM server 2.0 (http://www.cbs. dtu dk/services/TMHMM/). (b) Amide/aromatic region of $1 \mathrm{D}^{1} \mathrm{H}$ spectra of E1P47 peptide and its Trp to Ala mutants. (c) E1P47 indole NH region, 1D $1 \mathrm{H}$ spectra acquired in DMSO (below) and DPC micelles (above). (d) Amide/aromatic region chemical shift assignment of E1P47 1D ${ }^{1} \mathrm{H}$ spectra in DPC micelles.

After Pro-10, several $(\mathrm{i}, \mathrm{i}+3)$ correlations are in the "ambiguous" category because of spectral overlap, and thus cannot be confirmed. At the C-terminal region, some of the missing correlations for Phe-11 and Asp-12 are originated by peak broadening in presence of DPC, although there are some nonambiguous $\alpha \mathrm{N}(\mathrm{i}, \mathrm{i}+3), \mathrm{N}, \mathrm{N}(\mathrm{i}, \mathrm{i}+3)$ and $\alpha \beta(\mathrm{i}, \mathrm{i}+3)$ correlations that could indicate the presence of a second $\alpha$-helix. These results were also confirmed by circular dichroism analysis of E1P47 in DPC micelles (Figure S6a, Supplementary Information).

The experimental information derived from NOEs measurements was used as distance restraints to derive a three-dimensional structure of the peptide using molecular dynamics simulations. Specifically, information from 76 strong and 123 medium NOEs was used to impose interatomic distance restrains with intervals 1.8-2.8 $\AA$ and 1.8-3.8 $\AA$, respectively. After imposing all distance restrains, the peptide quickly adopts a defined structure in the molecular dynamics simulations. However, the structure obtained does not completely fulfil a few of the distance restrains, independently of the protocol used to impose them. A detailed analysis reveals that most of the unfulfilled restrains involve Trp14 that also exhibits a distorted side chain. Accordingly, we proceeded to study possible incompatibilities around this residue by switching on and off diverse restrains involving residue Trp14 systematically. This procedure permitted to identify a few conformations compatible with the restraints imposed exhibiting a common backbone structure but that differ in the orientation of Phe-11, Phe-13 and Trp-14 side chains. Figure 2 shows pictorially the superimposition of eleven diverse snapshots including the different conformations identified during the last 10 ns of the respective production runs. As can be seen, the structure adopted by the peptide can be described as a helixturn-helix. Specifically, the N-terminal helix involves residues 1-8, whereas the C-terminal helix involves residues 13-18. The two helical segments are joined by a loop involving residues Val-9. Pro-10, Phe-11 and Asp-12. Interestingly, the structure exhibits the side chains of the charged residues aligned forming a spine, whereas the side chains of the hydrophobic residues are directed in other directions.

The helical segment at the $\mathrm{N}$-terminus is stabilized by a salt bridge between Glu-4 and Lys-8 found in some of the conformations, consistent with the weak NOEs observed between protons of both side chains. In other conformations 
Glu-4 interacts with the amine N-terminus via a hydrogen bond, consistent with a weak NOE between the $C \beta$ of the former and the $\mathrm{NH}$ of the latter. Finally, the side chain of Trp-1 is very mobile, facing in most of the conformations neighbouring residues lle-1 and Leu-3.

The presence of the intermediate loop is consistent with several strong-medium NOE correlations between Val-9 and Phe-13 backbone and side chains protons that confirm that Val-9/Phe13 residues are not connected by a $a$-helix. Specifically, if Val- 9 were involved in a regular $\alpha$-helical conformation, the $\alpha \beta(i, i+4)$ distance will be around 5.0-7.0 $\AA$, showing very weak NOEs.27,28 In contrast, in our experiments suggest that this distance is shorter (strong-medium NOEs). Furthermore, one of the $V^{\prime}$ al9 $\mathrm{rCH}_{3}$ groups is much shielded (it appears at lower chemical shift than expected). confirming that these $\mathrm{CH} 3$ protons are near aromatic groups. Finally, another indication that the Phe-13 ring is interacting with Val-9 $(i-4)$ is the up-field displacement of the chemical shift of $\mathrm{Val}-9 \mathrm{a}-\mathrm{CH}$ atom (Table S2. $3.85 \mathrm{ppm})$. In a few of conformations the side chains of Tyr5 and Phe-11 exhibit distances of $\sim 5 \AA$ to the Pro-10 ring. respectively forming a sandwich stabilized by quadrupolequadrupole interactions. Interestingly, the motif Tyr-Pro-Tyr/Phe has been found in peptides with structures involving a $\beta$-turn secondary motif. ${ }^{29, x x}$

Figure 2. Superposition of the eleven conformations adopted by E1p47 in DPC micelles identified from MD simulations using diverse distance restrains derived from the NMR studies, showing two alternative conformations.

At the C-terminus, the entire set of conformations exhibit a salt bride between residues Asp-12 and Arg-15. Moreover, Asp-12 is simultaneously involved in a salt bridge with Lys-8 in most of the conformations, stabilizing the relative orientations of the two helices of the helix-turn-helix motif. The side chain of Trp-14 adopts two conformations. In one it appears close to Val-9 and Phe-13, consistent with several inter-residue strong NOEs. This conformation is stabilized by a quadrupole-quadruple interaction between the two aromatic side chains of Phe-13 and Trp-14. ${ }^{30}$ Actually, there are several NOEs between the side chains of these residues that permit to characterize the relative orientation

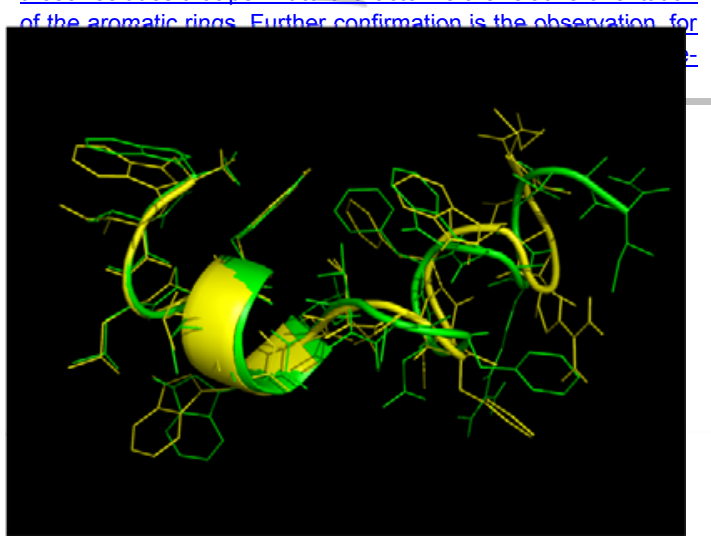

13 aromatic ring disappeared (moving to lower field is suspected) (Figure S5, Supplementary Information). This lack of a shielding effect could be related to the disappearance of the electronic effect in the chemical shift of the relative orientation between Phe-13/Trp-14 and validate the presence in the wild type peptide of a specific packing that produces the shielding of aromatic Phe-13 resonances in presence of Trp-14. ${ }^{31}$ In the other conformation, Trp-14 side chain moves away from Phe-13 to get in proximity to Phe-11, as supported by medium and weak NOEs between the two residues. Finally, the C-terminus is very mobile showing diverse conformations.

The experimental information derived from NOEs measurements was used as distance restraints to derive a three-dimensional structure of the peptide using molecular dynamics simulations. Spoifically, information from 76 strong and 123 modium NOEs was used to impose interatomic distance restrains with intervals $1.8-2.8 \AA$ and $1.8-3.8 \AA$, respectively. After imposing all distance restrains, the peptide quickly adopts a defined structure in the molecular dynamics simulations. Howover, the structure obtained does not completely fulfil a few of the distance restrains, independently of the protocol used to impose them. A detailed analysis reveals that most of the unfulfilled restrains involve Trp14. Accordingly, wo procodod to study possible incompatibilities around this residue by switching on and off diverse restrains systematically. This procedure permitted to identify two different conformations compatible with the restraints impos that oxhibit a similar backbon structure but that differ in the orientation of Phe-11 and Arg-15 side chains. Figure 2 shows pictorially the superimposition of a few snapshots involving the two conformations identified during the ast 10 ns of the respective production runs. As can be seon, the structure adopted by the peptide in any of the two conformations can be described as a helix-turn-helix. Specifically, the $\mathrm{N}$ terminal helix involves residues 1-8, whereas the $C$-terminal helix involves residues 12-18. The wo helical segments are joined by a loop involving residues Val-9, Pro-10 and Phe- 11 . Interestingly, the structure exhibits the side chains of the charged residues aligned in one side of the peptide, whereas the sido chains of sovoral aromatic rosidues including Trp-1; Tyr-5,

Phe-13 and Trp-14 are facing the opposite side. The two conformations exhibit a similar backbone structure, although they present a different scheme of inter-residue interactions at the $\mathrm{C}$-torminus. The holical sogment at the $\mathrm{N}$-torminus is stabilized by a salt bridge between Glu- 4 and Lys- 8 , consistent with the weak NOEs observed between protons of both side chains. In addition, the interaction between Trp-1 and Tyr-5 found in the MD dorived structure is supportod by strong to medium intra amino acid NOEs between aromatic protons and their backbone $\alpha / \beta$ protons.
Formatat: Superíndex

Formatat: Superíndex, Marca 
Figure 2. Superposition of the two conformations adopted by E1p47 in DPC micelles identified from MD simulations using diverse distance restrains derived from the NMR studies, showing two alternative conformations

The presence of the intermediate loop is consistent with several strong-modium NOE corrolations botwon Val-g and Pho-13 backbone and side chains protons that confirm that Val-9/Phe13 residues are not connected by a $\alpha$-helix. Specifically, if Val- 9 were involved in a regular a-helical conformation, the $\alpha \beta(i, i+4)$ distance will bo around $5.0-7.0 \AA$, showing vory woak NOEs. ${ }^{27,28}$ In contrast, in our experiments suggest that this distance is shorter (strong-medium NOEs). Furthermore, one of the Val9 YCH3 groups is much shielded (it appears at lower chemical shift than oxpected), confirming that these- $\mathrm{CH} 3$ protons are near aromatic groups. Finally, another indication that the Phe-13 ring is interacting with Val-9 $(i-4)$ is the upfield displacement of the chemical shift of $\mathrm{Val}-9 \mathrm{a}-\mathrm{CH}$ atom (Table S2, $3.85 \mathrm{ppm}$ ).

At the-C-terminus, one of the conformations oxhibits a salt bride between residues Asp-12 and Arg-15, whereas in the other the Arg-15 forms a hydrogen bond with the side chain of Phe- $11 .^{29}$ The former conformation permits a disposition of the side chain of Trp-14 close to Pho- 13 and Val-9, consistent with soveral inter-residue strong NOEs. In contrast, the other conformation permits the side chains of Phe-11 and Arg-15 to be in a hydrogen bond distance at the cost of separating the side chain of Trp-14 from those of Pho-13 and Val-9. The proton-aromatic ring hydrogen bond interaction is consistent with the observation of NOE cross peaks compatible with the proximity between Phe11 aromatic protons and Arg-15 side chain protons, but only Pho-11 3H-5H/Arg-15 cross poaks are unambiguous and do not overlap with other resonances (the integral cross peaks correspond to weak and very weak NOEs). Moreover, residues Phe-13 and Trp-14 at C-terminus may reinforce helix stability hrough quadrupole-quadrupole interactions betwoen the two aromatic rings since they show up at a distance of $\sim 5 \AA$, typical for this type of interaction. ${ }^{30}$-Actually, there are several NOEs between Phe-13 and Trp-14 that allow to characterize the relative orientation of the aromatic rings. Further confirmation is the observation, for the mutant W152A, that the resonances corresponding to Phe-13 aromatic ring disappeared (moving to lower field is suspected) (Figure S5, Supplementary Information). This lack of a shielding offoct could be rolated to the disappearance of the electronic effect in the chemical shift of the relative orientation between Phe-13/Trp-14 and validate the presence in the wild type peptide of a specific packing that produces the shiolding of aromatic Pho-13 rosonancos in presence of $\operatorname{Trp}-14 .^{31}$ An important point to mention is that the peptide bond between Val-9 and Pro-10 adopts a cis conformation in both structures. However, the conformation that exhibits a salt bridgo bon Asp-12 and Arg-15 can also be attained with the peptide bond in a trans conformation.

E1P47 Location in DPC micelles: diffusion NMR and evaluation of the effects of paramagnetic relaxation agents
Pulsed-field-gradient nuclear magnetic resonance (PFG-NMR) has been previously used to obtain the hydrodynamic size of lipid-complexedpeptides. ${ }^{32,33}$ To confirm the binding of E1P47 to DPC micelles, the translational diffusion coefficients for E1P47 and DPC in the binary complex were measured using this technique (Table 3). The aggregation number of DPC monomers per micelle in the literature varies between 56 and 80 , depending on the biophysical technique and the experimental conditions used. ${ }^{34-36}$ Taking into account these values and the DPC:peptide ratio $(100: 150 \mathrm{mM}: 0.5 \mathrm{mM})$ used, we estimated that we had enough DPC for the insertion of all E1P47 peptide molecules in the micelles. NMR measurements showed that the value of self-diffusion coefficients obtained for E1P47 is in the expected range for a peptide of similar length associated to micelles (Table 3 ) ${ }^{25,37}$ We were not able to measure the value of the free E1P47 peptide self-diffusion coefficient due to its aggregation in aqueous buffered media (without lipid) and without this value we couldn't calculate the partition coefficient of E1P47 in micelles. However, taking into account that the peptide is insoluble in water, we expect that most of the peptide is bound to DPC micelles. As control for viscosities changes due to the different composition in samples A and B (Table 3), we measured the diffusion coefficient for 4,4-dimethyl-4silapentane-1-sulfonic acid (DSS) proton resonance. The selfdiffusion coefficient measured for DPC micelles is in agreement with literature values. ${ }^{38}$ The results for DPC methylene chain resonances in the E1P47/DPC sample, with $\mathrm{a} \cong 10 \%$ decrease in the lipid self-diffusion coefficient in presence of E1P47 peptide (from 8.43 to $7.52 \times 10^{-11} \mathrm{~m}^{2} / \mathrm{s}$ ) could indicate a small increase in the micelle hydrodynamic radius $\left(R_{H}\right)$ that is associated to an increase in the lipid aggregation number ${ }^{25}$ or the reduction of DPC free fraction ${ }^{39,40}$ in presence of the peptide.

The diffusion NMR results confirm that E1P47 peptide is associated to DPC micelles, but not how is located in them (lying on the surface or immersed partially or completely inside the micelle?). To determine the position of E1P47 peptide in DPC micelles, paramagnetic lipid compounds wereadded. The paramagnetic species enhance the relaxation rates for nuclei close to the paramagnetic agent and the measurement of the changes in resonances amplitudes (or line width) allows a semiquantitative or qualitative analysis. ${ }^{41,42}$ As paramagnetic lipids, the spin $1 / 2$ doxyl group attached to different positions of stearic acid, 5-doxyl (nitroxide moiety located near the phosphate group) and 16-doxyl (nitroxide moiety located near the micelle center) were used. ${ }^{43}$

Table 3. Translational diffusion coefficient measured by NMR spectroscopy for peptide samples in DPC (A,B and C) and DPC micelles (D).

\begin{tabular}{lrr}
\hline & $\mathrm{D}\left(10^{-11} \mathrm{~m}^{2} \mathrm{~s}^{-1}\right)$ & $\mathrm{RSS}^{a}$ \\
\hline \multicolumn{1}{c}{ Sample A: E1P47+DPC } & $(\mathbf{0 . 5}: 50 \mathrm{mM})$ & \\
E1P47 $^{b}$ & $5.68 \pm 0.04$ & $4.00 \times 10^{-4}$ \\
E1P47 $^{c}$ & $5.73 \pm 0.03$ & $5.25 \times 10^{-5}$ \\
E1P47 $^{d}$ & $5.71 \pm 0.06$ & $9.48 \times 10^{-4}$ \\
E1P47 $^{e}$ & $5.83 \pm 0.07$ & $4.00 \times 10^{-4}$ \\
DPC $^{f}$ & $7.52 \pm 0.02$ & $8.30 \times 10^{-5}$ \\
DSS & $30.70 \pm 0.01$ & $1.25 \times 10^{-4}$ \\
\hline
\end{tabular}

Sample B: $\quad(0.5: 0.5: 50 \mathrm{mM})$

E1P47+FP23+DPC

$5.65 \pm 0.07 \quad 1.10 \times 10^{-3}$ 


\begin{tabular}{|c|c|c|}
\hline E1P47 $7^{c, g}$ & $6.51 \pm 0.10$ & $4.00 \times 10^{-4}$ \\
\hline $\mathrm{E} 1 \mathrm{P} 47^{d, g}$ & $6.38 \pm 0.05$ & $6.10 \times 10^{-3}$ \\
\hline $\mathrm{E} 1 \mathrm{P} 47^{\mathrm{e}, g}$ & $6.83 \pm 0.02$ & $4.40 \times 10^{-4}$ \\
\hline $\mathrm{DPC}^{f}$ & $7.51 \pm 0.03$ & $1.00 \times 10^{-4}$ \\
\hline DSS & $31.92 \pm 0.01$ & $1.34 \times 10^{-3}$ \\
\hline $\begin{array}{c}\text { Sample C: } \\
\text { E1P47+FP23+DPC }\end{array}$ & $(0.5: 0.5: 100 \mathrm{mM})$ & \\
\hline $\mathrm{E} 1 \mathrm{P} 47^{b}$ & $5.68 \pm 0.07$ & $1.10 \times 10^{-3}$ \\
\hline $\mathrm{E} 1 \mathrm{P} 47^{c, g}$ & $6.10 \pm 0.03$ & $1.22 \times 10^{-5}$ \\
\hline $\mathrm{E} 1 \mathrm{P} 47^{d, g}$ & $6.07 \pm 0.10$ & $5.00 \times 10^{-4}$ \\
\hline $\mathrm{E} 1 \mathrm{P} 47^{e, g}$ & $6.67 \pm 0.04$ & $5.00 \times 10^{-4}$ \\
\hline $\mathrm{DPC}^{f}$ & $6.80 \pm 0.04$ & $3.00 \times 10^{-4}$ \\
\hline DSS & $21.76 \pm 0.01$ & $1.15 \times 10^{-3}$ \\
\hline Sample D: DPC & $50 \mathrm{mM}$ & \\
\hline $\mathrm{DPC}^{f}$ & 8.43 & $8.85 \times 10^{-5}$ \\
\hline DSS & 31.16 & $2.43 \times 10^{-4}$ \\
\hline
\end{tabular}

[a] RSS (Residual Sum of Squares). [b] E1P47 peptide Trp-14 side chain region 7.45-7.52 ppm. [c] E1P47 peptide methyl region 0.93-0.81 ppm. [d] E1P47 peptide W145 side chain region 7.23-7.26 ppm. [e] E1P47+FP23 Phe region 7.23-7.16 ppm. [f] DPC region 1,26-1,14 ppm. [g] Resonances from E1P47+FP23

A water-soluble paramagnetic metal salt $\left(\mathrm{GdCl}_{3}\right.$, spin 3/2) was also tested, allowing characterizing the residues that are lying outside the DPC micelles. Upon addition of $3 \mathrm{mM} 5$-doxyl stearic acid (5-DSA) to E1P47/DPC micelles (ratio 5-DSA:DPC 1:70, one spin-label per micelle molecule), we observed important chemical shift changes and an increase in the intensity of most backbone amide resonances in the $1 \mathrm{D}{ }^{1} \mathrm{H}$ spectra (amide resonance for Glu-4, Tyr-5, Phe-11, Asp-12, Phe-13, Trp-14 and Arg-15; see Figure S7a, Supplementary Information), whereas aromatic resonances showed a small decrease in intensity and very small broadening. This trend is also observed in the $2 \mathrm{D}$ NOESY ${ }^{1} \mathrm{H}-{ }^{1} \mathrm{H}$ spectra (Figure S7b, Supplementary Information). These results imply that the presence of the 5-DSA spin-label has some influence on the conformation of E1P47 bound DPC Qualitatively, the resolution improvement of overall cross-peaks in the 2D NOESY spectra seems to indicate that the presence of the nitroxide atoms near the DPC phosphate group could destabilize a little the interaction between the peptide and the lipid, improving the peptide mobility inside the micelles. Also, this is an indirect observation that the most part of the peptide amide groups is at the level of DPC phosphate moiety in the micelle. The Gd3+ paramagnetic cations are located in the aqueous phase, at the vicinity of the cationic head group of DPC and, are expected to cause selective broadening of residues exposed to the solvent

a)
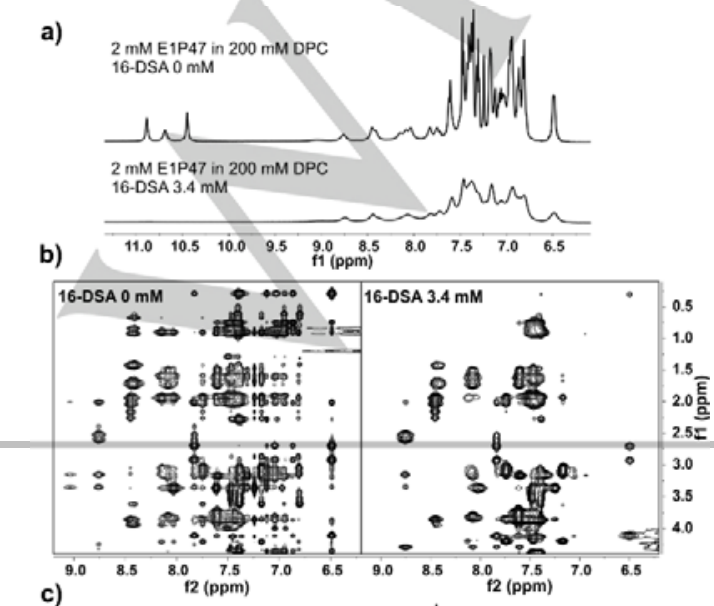

c)

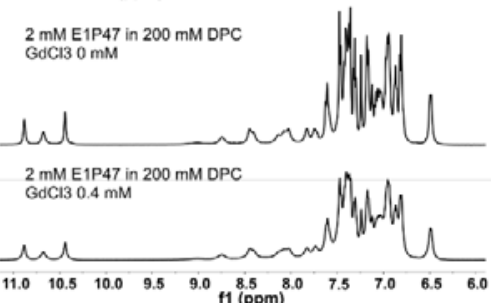

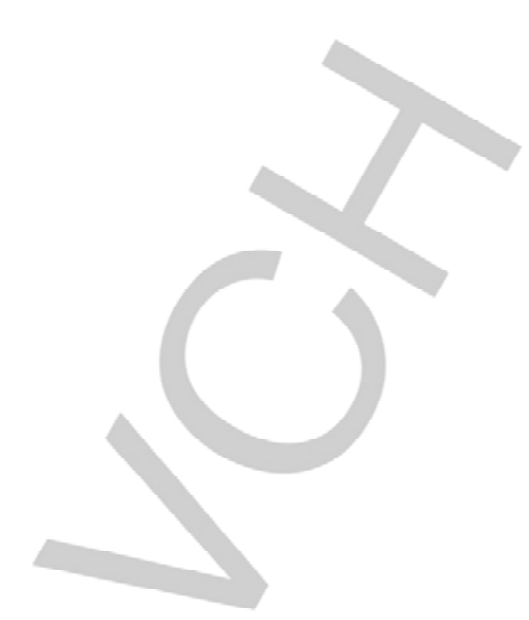

Figure 3. Effect of paramagnetic compounds in NMR spectra of $2 \mathrm{mM}$ E1P47 peptide in $200 \mathrm{mM}$ DPC-d38 micelles, $10 \mathrm{mM}$ sodium phosphate, $\mathrm{pH}=6.2$ and $10 \% \mathrm{D}_{2} \mathrm{O}$. (a) $1 \mathrm{D}{ }^{1} \mathrm{H}$ NMR spectra with 0 and $3.4 \mathrm{mM}$ of $16-\mathrm{DSA}$; (b) $2 \mathrm{D}{ }^{1} \mathrm{H},{ }^{1} \mathrm{H}-$ NOESY spectra with 0 and $3.4 \mathrm{mM}$ of $16-\mathrm{DSA}$; (c) $1 \mathrm{D}{ }^{1} \mathrm{H}$ NMR spectra with 0 and $0.4 \mathrm{mM}$ of GdCl3; (b) $2 \mathrm{D}{ }^{1} \mathrm{H},{ }^{1} \mathrm{H}-\mathrm{NOESY}$ spectra with 0 and $0.4 \mathrm{mM}$ of $\mathrm{GdCl} 3$.

or close to the water-micelle interface (mainly affect the proton and carbon signals from the methylene groups close to the choline head group). Addition of $0.4 \mathrm{mM} \mathrm{Gd}^{3+}$ led to the uniform retention of the $70 \%$ of the E1P47 resonance intensities, indicating that E1P47 was not exposed to the solvent but embedded in the DPC micelles (Figure $3 c-d$ and Figure S8a, Supplementary Information). Using 16-DSA, with a 16-DSA/DPC ratio of $\sim 1: 70$, the resonances of Trp-7 and Val- 9 decreased to $10-20 \%$ of the initial intensity (Pro-10 was not observed due to the lack of amide proton and resonances from Lys- 8 are overlapped with other resonances), and those corresponding to residues located on both sides of these amino acids presented a reduction in intensity between a 40 to $70 \%$ (Figures $3 a-b$ and Figure S7, Supplementary Information). The results obtained with 16-DSA suggest that E1P47 is inserted inside the DPC micelles, with the most quenched residues located toward the micelle core centre (Trp-7, Val9 and Pro-10). The most charged residues (Glu-4, Asp-12 and Arg15) present intermediate quenching level (between 40 and $75 \%$ ), in agreement with the conformations identified by MD analysis. The effects observed by 5-DSA, 16-DSA and $\mathrm{GdCl}_{3}$ and the observation of intermolecular NOE cross peaks between Glu-4 and Asp-12 side chain protons with methyl's from DPC choline head group (data not shown), indicate that E1P47 peptide is inside the micelle, likely lying nearly parallel to the surface, with negative charged side chains oriented to choline head group and the hydrophobic 5 - residues pointing to the micelle core (Figure S8b, Supporting Information) 


\section{Interaction between E1P47 and its viral target, FP23}

One of the known requirements of HIV-1 virus-cell fusion is the formation of a pre-fusion intermediate of the trimeric gp41 glycoprotein that folds into a six helical bundle structure leading to the apposition of the viral and cellular membrane. ${ }^{44,45}$ In the prefusion intermediate the $\mathrm{N}$-terminal region of gp41 (FP) is inserted into the cell membrane, while its transmembrane region (TM) is anchored to the viral membrane. The folding of $\mathrm{N}$ - and C- terminal heptad repeats of gp41 to form a triple stranded coiled-coil is responsible for lowering the free-energy barrier required for viral and target cell membrane fusion. After the confirmation that E1P47 is structured as a helix-turn-helix lying inside a membrane-mimicking environment, we sought to validate and characterize the interaction between E1P47 and FP23 peptides in DPC micelles. NMR chemical shift has been used as a probe to study protein-protein (or peptide-peptide) interaction and to map the binding site. 46,47 The association of E1P47 and FP23 in the presence of DPC micelles was studied by titrating E1P47 in DPC micelles with increasing amounts of FP23 (previously dissolved in DMSO) until 1:1 ratio and monitoring the changes by acquisition of consecutive $1 \mathrm{D}{ }^{1} \mathrm{H}$ NMR experiments (Figure S9, Supplementary Information).

FP23 peptide hydrophobicity limited the working concentration range, so using low E1P47 peptide concentration in DPC/HEPES buffer to avoid Fp23 aggregation and precipitation during titration was necessary. ${ }^{48,49}$ Chemical shift changes for E1P47 amide groups of Leu3, Glu4, Asp12, Phe13, Trp-14 and Arg-15, the NH proton from indole side chain of Trp-1, Trp-7 and Trp-14 and the aromatic protons of Tyr-5, Trp-7, Phe-11, Phe-13 and Trp-14, were observed. In addition, line broadening was observed for some peaks (as 3,5H for Tyr-5 or 2,6H Phe-11, Figure S9b). We initially attribute these chemical shift/lineshape variations to a change of conformational dynamics within E1P47 due to peptide-peptide interaction and not a consequence of a large increase in correlation time after FP23 addition (validation by Diffusion NMR experiment is presented onwards). These changes are more easily followed using the tryptophan $\mathrm{NH}$ indole proton. In Figure 4a, the variations in E1P47 three tryptophan's indole region upon titration with FP23 are shown. Due to E1P47 hydrophobicity and affinity for DPC, we expected that nearly all E1P47 molecules were inserted in DPC micelles and micellar E1P47 didn't experience rapid exchange with residual free peptide in solution.

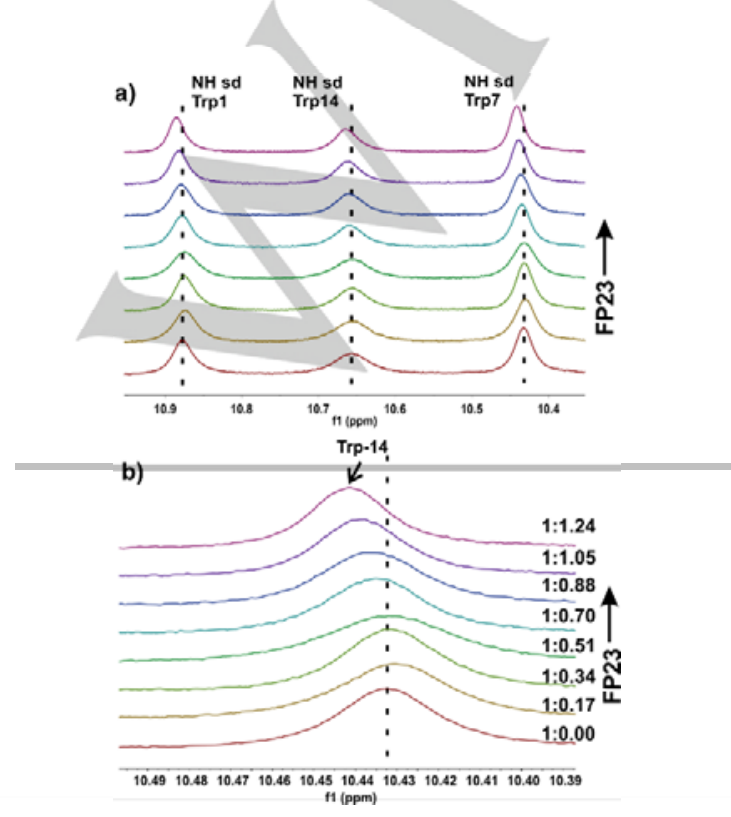

Figure 4. Study of the interaction between the peptides E1P47 and HIV-1 FP23. The association of E1P47 with FP23 was characterized by titration of previously pre-formed E1P47/DPC complexes with increasing amounts of FP23 (from 1:100 total peptide:DPC to 1:50 total peptide:DPC, in $20 \mathrm{mM}$ HEPES, $\mathrm{pH}=6.2,300 \mathrm{~K}$.

So, in the titration (E1P47 concentration nearly constant) the contribution of mixed fast-intermediate regime dynamic processes could not be discarded (E1P47 conformational change upon FP23 binding, change of E1P47 interaction with micelles upon FP23 binding and exchange of E1P47 between micelles). The resonance for E1P47 Trp-14 NH indole broadened until mid-titration (1:0.51 E1P47:FP23) and then recovered around 1:1 ratio (Figure $4 \mathrm{~b}$ ). In this case, the initial broadening followed with the narrowing of E1P47 resonances for FP23 ratios $>0.5$ is compatible with mixed fast/intermediate exchange processes on the NMR time scale. Analysis of NMR lineshapes can yield information on the affinities/kinetics of ligand binding but, ${ }^{50-51}$ due to the difficulties to stablish a simple model, the calculation of a $K_{\mathrm{d}}$ for E1P47-Fp23 is complex and not attempted. To validate the formation of the complex between the two peptides in DPC micelles, the inverse titration experiments, maintaining constant FP23 concentration (previously dissolved in DPC-d38 micelles) and adding increasing amounts of E1P47 until 1:1 ratio, were also acquired. The known chemical shift assignment of FP23 in DPC micelles was used for comparison purposes ${ }^{17,19,52,53}$ and was complemented by acquiring the $2 \mathrm{D}{ }^{1} \mathrm{H}-{ }^{-1} \mathrm{H}$ NOESY of FP23 peptide in equivalent conditions (same peptide:DPC ratio, $\mathrm{pH}$ and temperature) that for our titration experiments. Using $2 \mathrm{D}$ NOESY spectra and literature values, we could assign some of the FP23 residues that experienced chemical shift changes after E1P47 addition. Due to concentration limitations (use of small concentration to avoid peptide aggregation) and the presence of overlapped E1P47/FP23 resonances in FP23 titration with E1P47, only the chemical shift variation of a few FP23 resonances was identified unambiguously. In particular, we could observe chemical shift changes for the amide groups of Gly-3, Ile-4, Gly-5, Leu-7, Phe-11 and aromatic Phe-8 and/or Phe-11 protons (Figure S10, Supplementary Information).

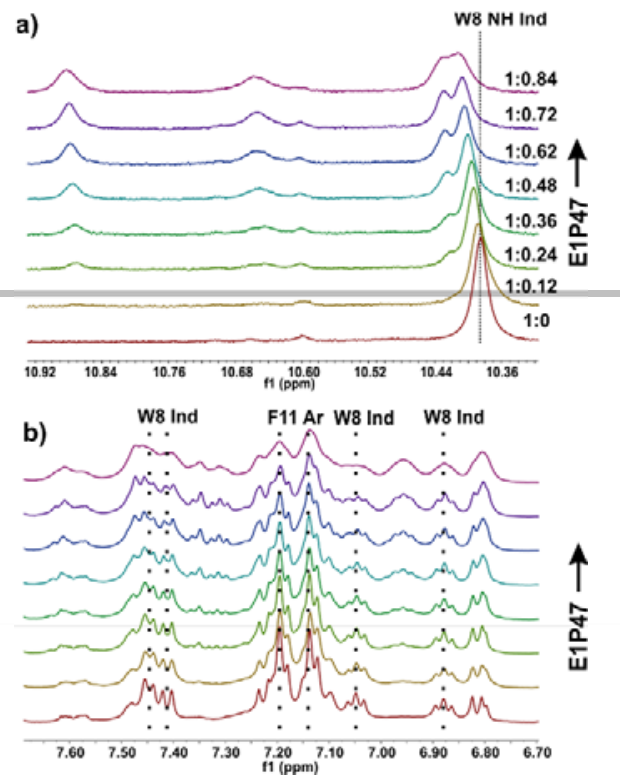


micelles or/and peptide aggregation). For the ternary complex (sample B, Table 3), the diffusion coefficient of DPC remains unaltered, indicating that micelles aggregation number/size or DPC free fraction doesn't change significantly after FP23 addition. The diffusion coefficient of several E1P47 resonances showed a small increase in those regions with overlapped FP23 and E1P47 signals (samples B and $C$, entries $c, d$ and $e$ corresponding to overlapped Leu/le/Val methyl's and Phe aromatic protons from both peptides). Only the value for region $b$ corresponds to E1P47 pure coefficient diffusion in micelles. This value remained constant in the three samples ( $A, B$ and $C$ ), regardless of the composition. Due to resonance overlap, it was not possible to measure the diffusion coefficient of FP23 in DPC+E1P47 complex, but the peak e (Table 3) contains mainly contributions for FP23 peptide and the measured diffusion coefficient, $6.83 \times 10^{-11} \mathrm{~m}^{2} / \mathrm{s}(300 \mathrm{~K}, 0.5 \mathrm{mM})$ is very similar to the diffusion coefficient previously measured for FP23 in DPC

$\begin{array}{lllll}\text { Figure } & 5 . & \text { The association of FP23F8W }\end{array}$ (AVGIGALWLGFLGAAGSTMGAAS) with E1P47 was characterized by titration of previously pre-formed FP23 F8W/DPC complexes with increasing amounts of E1P47 (1:100 total peptide:DPC to 1:50 total peptide:DPC, in $20 \mathrm{mM}$ HEPES, $\mathrm{pH}=6.2,300 \mathrm{~K}$ ).

In the two conditions used for FP23 titration (different buffer, initial FP23 concentration and FP23:DPC ratio), we observed a progressive broadening of FP23 resonances when increasing E1P47 amounts (Figures S10 and S11, Supplementary Information). It is known that for low concentration peptide:detergent ratios ( $\geq 1: 50,0.02$ or lower), lysine or aspartic-tagged FP23 peptide is in a helical conformation from Ile4 to Ala15. ${ }^{17,19,53}$ For unmodified FP23 peptide and high FP23 peptide:detergent ratios (1:10, $2 \mathrm{mM} F P 23)$, aggregation has been observed and, using CD and FTIR studies, that has been associated to the presence of $\beta$-conformation. ${ }^{4}$ Considering that, during E1P47:FP23 titrations, the total peptide:detergent ratio is in the low range and that we are working at low FP23 concentration $(\sim 0.2-0.3 \mathrm{mM})$, we propose that the NMR observed line broadening is not originated by FP23 aggregation but for an intermediate exchange binding process. To further validate these results, we repeated the titration using a FP23 mutant that contains a Tryptophan in position 8 instead of Phenylalanine (F8W). This analogue conserves fusogenic activity and adopts the same conformations in solution than the wild type peptide. ${ }^{54}$ The advantage of this mutant is that the tryptophan resonance could be followed unambiguously. F8W FP23 aromatic and indole group region of the E1P47 titrated NMR spectra are displayed in Figure 5. A progressive chemical shift change and broadening of the Trp- 8 indole $\mathrm{NH}$ resonance were observed. In this case, the maximum broadening didn't happen for F8W FP23:E1P47 1:0.5 ratio (in contrast of E1P47 titration with FP23), perhaps associated to different $k_{\text {off }}$ for complexed species.

The simultaneous presence of both peptides in DPC micelles was evaluated by diffusion NMR (Table 3 ). The measurement by NMR of the diffusion coefficient for the E1P47+FP23/DPC samples had two objectives; to confirm that both peptides could be inserted in the micelles at the same time and that the resonance broadening observed during titration is not originated with a decrease on peptide correlation time (due to the increase of the aggregation number of DPC in micelles in presence of the | two peptides, due to the intermolecular association of DPC micelles $\left(7.0 \times 10^{-11} \mathrm{~m}^{2} / \mathrm{s}, 298 \mathrm{~K}, 0.5 \mathrm{mM} \mathrm{FP} 23\right)^{52}$ confirming that FP23 peptide also associates with DPC micelles in presence of E1P47 peptide. For sample B, FP23 calculated bound molar fraction is 0.91 (additional analysis in Material and Methods, Supporting Information), so we hypothesize that the contribution of the free FP23 component (0.09 molar fraction) increases his observed diffusion coefficient in comparison to the value for E1P47 peptide. The distribution/number of side chain charges and hydrophobic groups seems determinant for peptide binding to micelles and E1P47 and FP23 peptides are very different in those features (Figure S12, Supporting Information). ${ }^{55-57}$ According to MD calculations, Our-our inhibitor ---E1P47 peptide, - contains clustersexhibits a spine of charged residues aligned in one side of the molecule, with the and at loast 4 -aromatio hydrophobic residues pointing in on the oppositediverse side directions opposite to the spineaccording to $\mathrm{MD}$, with that confers a structure highly favourable for its the whole-insertion in DPC micelles. Besides, our diffusion NMR results confirm that E1P47 is nearly fully bound to DPC micelles. We note that the micelles are much larger than the peptides; thus the accommodation of several peptide molecules in one micelle is possible without a size/aggregation number change in micelles. Taking into account the known DPC aggregation number (65-80) and that the E1P47 diffusion coefficients remains the same in presence of FP23, our results suggest that both peptides could coexist in the same micelle without a significant change in micellar size and that the broadening observed during NMR titrations is originated by FP23/E1p47 interaction.

On the other hand, to confirm the specificity of the E1P47-FP23 interaction, we performed a titration (addition of FP23 to SCR in DPC) and measured SCR diffusion coefficients in DPC with/without FP23, using the same control peptide that in cellular assays (SCR, Table 2). The results are shown in Figure S13 (Supporting Information) and are according to the fact that SCR and FP23 could not bind simultaneously to lipid micelles due to the much higher affinity of FP23 to membrane environment. In addition, the secondary structure of SCR obtained by circular dichroism agrees well with a $\beta$-strand conformation that can explain the absence of any kind of anti-HIV-1 activity for this peptide sequence.

Some authors have described that FP and transmembrane domain (TM) are in close proximity during viral fusion suggesting that the N-terminal domain of gp41 interacts with the TM and/or with the membrane proximal external region (MPER) 
contributing energy to the membrane fusion reaction ${ }^{58,59}$ Although the NMR spectroscopy study on the structure and dynamics of the homotrimeric gp41 complex reconstituted in DPC micelles carried by the group of Bax excluded a significant interaction between $\mathrm{FP}$ and $\mathrm{TM}^{60}{ }^{60}$ recent studies on the intermediary steps of the fusion process demonstrates that trimerization of HIV-1 gp41 ectodomain bound to dodecylphosphocholine micelles requires the presence of both the fusion peptide proximal region (FPPR) and the MPER. ${ }^{61}$ The structural study carried out by Buzon demonstrated that most of the conserved residues of MPER are hydrophobic residues that contribute to hydrophobic interactions with FPPR being these domains critical for stabilizing the six-helix bundle formation in a detergent environment. ${ }^{62}$ The structure of the MPER in DPC micelles is characterised by a helix-hinge-helix motif with the aromatic residues buried on the membrane. ${ }^{63}$ The disruption of the structural motif by double alanine mutations of MPER reduced the fusion activity and viral entry indicating that the structural conformation of this region is relevant to maintain the fusogenic activity of the protein. ${ }^{64}$ Comparatively, the structure in DPC micelles of E1P47 peptide is very similar to the MPER region of HIV-1 gp41. Our results demonstrated that this conformation is also important for maintaining the inhibitory activity of the peptide since the change of the helix-turn-helix by a $\beta$-sheet conformation, demonstrated by $C D$ on the scrambled sequence in DPC micelles (Figure S6, Supporting Information), determines the loss of inhibition activity. Based on this background and considering the structural homology between the E1P47 peptide and the MPER, the inhibition mechanism of the E1P47 could also be related to the impairment of the interaction of the FP peptide with other membrane active domains of HIV-1 gp41, such as MPER, that are pivotal for the stabilization of the fusion active molecular structure.

Thus, the interaction of E1P47 inhibitor with the FP at the membrane might block further gp41 refolding required for membrane fusion either avoiding the clustering of the FP on the membrane and/or hindering the interaction of FP with MPER/TM regions.

\section{Conclusions}

NMR data reveal that E1P47 peptide forms a helix-turn-helix in zwitterionic micelles. Antiviral structure-activity studies confirm the importance of some structural elements in E1P47 anti-HIV-1 potency, like the N-terminal $\alpha$-helix, the Pro-10 in the hinge region and the Asp-12 in the second helix motif. NMR measurement of E1P47 diffusion coefficient and the effect of paramagnetic compounds on E1P47 NMR spectra indicate that E1P47 is soaked inside DPC micelles, lying parallel to the micelle surface. Besides, our results show the first evidence that the interaction between E1P47 and its viral target (FP23) takes places at membrane level. We propose that E1P47 could interfere with those domains in HIV-1 that are critical for stabilizing the six-helix bundle formation in a membranous environment and consequently, inhibit the viral entry.Main Text Paragraph.

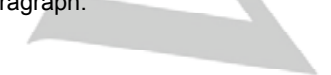

\section{Experimental Section}

Experimental Details.

\section{Computational studies}

Restrained molecular dynamics was used to provide a threedimensional structure of E1P47 compatible with the structural information provided by NMR spectroscopy. For this purpose, we used as starting structure the extended conformation of the peptide with its $\mathrm{N}$-terminus charged and the C-terminus amidated. Side chains of Glu-4, Lys- 8 , Asp-12, and Arg-15, were considered as charged. The environment of the peptide was simulated using a generalized Born model (Anandakrishnan et al., 2015) with an intermediate dielectric constant $(\varepsilon=32.7)$. were performed using distance constrains deduced from 76 strong and 123 medium NOEs signals and imposing a 1.8-2.8 $\AA$ and 2.8-3.8 $\AA$ distance restriction with a force constant of $1 \mathrm{kcal}$ $\mathrm{mol}^{-1} \AA^{-2}$ to the corresponding atoms involved. Since the simulation including all the restrictions dis not provide satisfactory results, we carried out two simulations lifting part of the restrains on the Trp-14 residue. In the first simulation, all the retrictions regarding the Trp-14 were lifted and for the second only the medium intensity restrictions were lifted. A 2fs integration step was used for the molecular dynamics runs after constraining all the bonds involving hydrogen atoms using the SHAKE algorithm (Miyamoto et al., 1992).
Formatat: Tipus de lletra: (Per defecte) Arial, 8,5 pt

Formatat: Tipus de lletra: (Per defecte) Arial, 8,5 pt

Formatat: Tipus de lletra: (Per defecte) Arial, 8,5 pt

Formatat: Tipus de lletra: (Per defecte) Arial, 8,5 pt

Formatat: Tipus de lletra: (Per defecte) Arial, 8,5 pt

Formatat: Tipus de lletra: (Per defecte) Arial, 8,5 pt

Formatat: Tipus de lletra: (Per defecte) Arial, 8,5 pt

Formatat: Tipus de lletra: (Per defecte) Arial, 8,5 pt

Formatat: alemany (Alemanya)

\section{Notes}

Accession codes Protein Data Bank

2PV6: HIV-1 gp41 Membrane Proximal Ectodomain Region peptide in DPC micelle. 
XXYY: (GBV-C) E1 protein E1P47 peptide in DPC micelle

\section{Acknowledgements}

This study is supported by a Grant CTQ2015-63919-R from the Ministerio de Economía y Competitividad, Spain. The $500-\mathrm{MHz}$ spectrometer was purchased in part through a Grant from MINECO-FEDER CSIC13-4E-2076. Partial financial support from the Spanish National Research Council (CSIC) is also gratefully acknowledged.

Keywords: HIV-1 • FP23 • DPC micelles • fusion inhibitor • keyword $5 \cdot$ keyword 6

\section{References}

(1) Haqqani, A. A., Tilton, J. C. Antiviral research 2013, 98, 158170.

(2) Munch, J., Standker, L., Forssmann, W. G., Kirchhoff, F. Nat. Rev. Microbiol. 2014, 12, 715-722.

(3) Galatola, R., Vasconcelos, A., Perez, Y., Cruz, A., Pujol, M., Alsina, M. A., Gomara, M. J., Haro, I. Eur. J. Med. Chem 2014, 86, 589.

(4) Leslie, G. J., Wang, J., Richardson, M. W., Haggarty, B. S. Hua, K. L., Duong, J., Secreto, A. J., Jordon, A. P., Romano, J., Kumar, K. E., DeClercq, J. J., Gregory, P. D. June, C. H., Root, M. J., Riley, J. L., Holmes, M. C., Hoxie, J. A. PLoS pathogens 2016, 12, e1005983.

(5) Ju, T., Hu, D., Xiang, S. H., Guo, J. Bioorg. Chem. 2016, 68 105-111.

(6) Wild, C.T., Shugars, D.C., Greenwell, T.K., McDanal C.B. and Matthews, T.J. Proc. Natl. Acad. Sci. USA 1994, 91 9770-9774.

(7) Tan, Q., Zhu, Y., Li, J., Chen, Z., Han, G. W., Kufareva, I., Li, T., Ma, L., Fenalti, G., Li, J., Zhang, W., Xie, X., Yang, H., Jiang, H., Cherezov, V., Liu, H., Stevens, R. C., Zhao, Q. Wu, B. Science 2013, 341, 1387-1390.

(8) Forssmann, W. G., The, Y. H., Stoll, M., Adermann, K. Albrecht, U., Tillmann, H. C., Barlos, K., Busmann, A., Canales-Mayordomo, A., Gimenez-Gallego, G., Hirsch, J., Jimenez-Barbero, J., Meyer-Olson, D., Munch, J., PerezCastells, J., Standker, L., Kirchhoff, F., Schmidt, R. E. Sci. Transl. Med. 2010, 2 (63), 63re3.

(9) Munch, J., Standker, L., Adermann, K., Schulz, A., Schindler M., Chinnadurai, R., Pohlmann, S., Chaipan, C., Biet, T., Peters, T., Meyer, B., Wilhelm, D., Lu, H., Jing, W., Jiang, S., Forssmann, W. G., Kirchhoff, F. Cell 2007, 129, 263275.

(10) Gomara, M. J., Sanchez-Merino, V., Paus, A., MerinoMansilla, A., Gatell, J. M., Yuste, E., Haro, I. Biochim. Biophys. Acta 2016, 1860, 1139-1148.

(11) Sanchez-Martin, M. J., Hristova, K., Pujol, M., Gomara, M. J., Haro, I., Alsina, M. A., Busquets, M. A., J. Colloid Interface Science 2011, 360 (1), 124-31.

(12) Yang, R., Prorok, M., Castellino, F. J., Weliky, D. P. J. Am Chem Soc 2004, 126, 14722-14723.(13) Venken, T., Voet, A., De Maeyer, M., De Fabritiis, G., Sadiq, S. K. J. Chem. Theory Comput. 2013, 9, 2870.

(14) Dai, Z., Tao, Y., Liu, N., Brenowitz, M. D., Girvin, M. E., Lai, J. R. Biochemistry 2015, 54, 1589-1599.

(15) Sackett, K., Nethercott, M. J., Zheng, Z., Weliky, D. P. J. Mol. Biol. 2014, 426, 1077-1094.

(16) Qiang, W., Sun, Y., Weliky, D. P. Proc. Natl. Acad. Sci. USA 2009, 106, 15314-15319.
(17) Jaroniec, C. P., Kaufman, J. D., Stahl, S. J., Viard, M., Blumenthal, R., Wingfield, P. T., Bax, A. Biochemistry 2005, 44, 16167-16180.

(18) Li, Y., Tamm, L. K. Biophys. J. 2007, 93, 876-885

(19) Gabrys, C. M., Weliky, D. P. Biochim. Biophys. Acta 2007 $1768,3225-3334$

(20) Lai, A. L., Moorthy, A. E., Li, Y., Tamm, L. K. J. Mol. Biol. 2012, 418, 3-15.

(21) Braun, W., Wider, G., Lee, K.H., Wuthrich, K. J. Mol. Biol. 1983, 169, 921-948.

(22) Pellegrini, M., Mierke, D.F. Biochemistry 1999, 38,1477514783.

(23) Hsu, S. T., Breukink, E., Bierbaum, G., Sahl, H. G., de Kruijf, B., Kaptein, R., van Nuland, N. A., Bonvin, A. M. J. Biol. Chem. 2003, 278, 13110-13117.

(24) Mohr, E. L., Stapleton, J. T. J. Viral. Hepat. 2009, 16, 757768.

(25) Kallick, D.A., Tessmer, M.R.: Watts, C.R., Li, C.H. J. Mag. Res. Series B, 1995, 109, 60-65.

(26) Hiruma-Shimizu, K., Shimizu, H., Thompson, G. S. Kalverda, A. P., Patching, S. G. Mol. Membr. Biol. 2015, 32, 139-155.

(27) Wuthrich, K., Billeter, M., Braun, W. J. Mol. Biol. 1983, 169, 949-961.

(28) Wuthrich, K., Billeter, M., Braun, W. J. Mol. Biol. 1984, 180 715-740.

(29) Meng, H. Y.; Thomas, K. M.; Lee, A. E.; Zondlo, N. J. Biopolymers 2006, 84, 192 -204.Gallivan, J.P., Dougherty D. A. Proc. Natt. Acad. Sci. USA 1999, 96, 9459-9464.

(30)Meyer, E. A., Castellano, R. K., Diederich, F. Angew. Chem. Int. Ed. 2003, 42, 1210-1250.

(31) Samanta, U., D. Pal and P. Chakrabarti. Acta Crystallogr. D Biol. Crystallogr. 1999, 55, 1421-1427.

(32) Maler, L. Mol. Membr. Biol. 2012, 29, 155-176.

(33) Barhoum, S., V. Booth and A. Yethiraj. Eur. Biophys. J. 2013, 42, 405-414.

(34) Lauterwein, J., C. Bosch, L. R. Brown and K. Wuthrich Biochim Biophys Acta 1979, 556, 244-264.

(35) Lipfert, J., L. Columbus, V. B. Chu, S. A. Lesley and S. Doniach. J. Phys. Chem. B 2007, 111, 12427-12438.

(36) Oliver, R. C., J. Lipfert, D. A. Fox, R. H. Lo, S. Doniach and L. Columbus. PLoS One 2013, 8, e62488.

(37) Yao, S., D. K. Weber, F. Separovic and D. W. Keizer. Eur. Biophys. J . 2014, 43, 331-229.

(38) Sikorska, E., D. Wyrzykowski, K. Szutkowski, K. Greber, E. A. Lubecka and I. Zhukov. Journal of Thermal Analysis and Calorimetry 2015, 123, 511-523.

(39) Barhoum, S., Palit, S., Yethiraj, A. Prog. Nucl. Magn. Reson. Spectrosc. 2016, 94-95, 1-10.

(40) Gobl, C., M. Dulle, W. Hohlweg, J. Grossauer, S. F. Falsone O. Glatter and K. Zangger. J. Phys. Chem. B 2010, 114, 4717-4724.

(41) Damberg, P., Jarvet, J., Gräslund, A. Methods in Enzimology 2001, 339, 271.

(42) Schrank, E., G. E. Wagner and K. Zangger. Molecules 2013 18, 7407-7435.

(43) Brown, L. R., C. Bosch and K. Wuthrich. Biochim. Biophys Acta 1981, 642, 296-312.

(44) Tamm, L. K., Lee, J., Liang, B. Structure 2014, 22 (9), 1225-6.

(45) Apellaniz, B., Huarte, N., Largo, E., Nieva, J. L. Chemistry and physics of lipids 2014, 181, 40-55.

(46) Eaton, H.L., Austin, R.E., Fesik, S.W. and Martin, S.F. Proc. Natl. Acad. Sci. USA 1989, 86, 9767-9769.

(47) Arac, D., T. Murphy and J. Rizo. Biochemistry 2003, 42, 2774-2780.

(48) Yang, J., Gabrys, C.M. and Weliky. D.P. Biochemistry 2001 $40,8126-8137$
Formatat: Tipus de lletra: Cursiva

Formatat: Tipus de lletra: Negreta

Formatat: anglès (EUA) 
(49) Yang, J., Prorok, M., Castellino, F.J. and Weliky, D.P. Biophys. J. 2004, 87, 1951-1963.

(50) Kovrigin, E. L. Journal of biomolecular NMR 2012, 53, 257270.

(51) Feeney, J., Batchelor, J. G., Albrand, J. P., Roberts, G. C. K. J Mag Res (1969) 1979, 33, 519-529.

(52) Morris, K. F., Gao, X. and Wong, T.C. Biochim. Biophys. Acta 2004, 1667, 67-81.

(53) Tamm, L. K., Lai, A.L., and Li, Y. Biochim. Biophys. Acta 2007, 1768, 3052-3060.

(54) Saez-Cirion, A. and Nieva, J.L. Biochim Biophys Acta 2002 1564, 57-65.

(55) Whitehead, T. L., Jones, L. M., Hicks, R. P. 2 J Biomol Struct Dyn 2004, 21 (4), 567-576.

(56) Gao, X., Wong, T. C. Biopolymers 2001, 58, 20-31.

(57) Yu, H. Y., Yip, B. S., Tu, C. H. Chen, H. L., Chu, H. L., Chih Y. H., Cheng, H. T., Sue, S. C., Cheng, J. W. Biochim. Biophys. Acta 2013, 1828, 2720.

(58) Reuven, E. M., Dadon, Y., Viard, M., Manukovsky, N., Blumenthal, R. Shai, Y. Biochemistry 2012, 51, 2867-2878.

(59) Lorizate, M., Huarte, N., Saez-Cirion, A., Nieva, J. L. Biochim. Biophy.s acta 2008, 1778, 1624-1639.

(60) Lakomek, N. A., Kaufman, J. D., Stahl, S. J., Louis, J. M. Grishaev, A., Wingfield, P. T., Bax, A. Angew. Chem. Int. Ed. 2013, 52, 3911-3915.

(61) Louis, J. M., Baber, J. L., Ghirlando, R., Aniana, A., Bax, A., Roche, J. PloS One 2016, 11 (8), e0160597.

(62) Buzon, V., Natrajan, G., Schibli, D., Campelo, F., Kozlov, M. M., Weissenhorn, W. PLoS pathogens 2010, 6 (5), e1000880.

(63) Sun, Z. Y., Oh, K. J., Kim, M., Yu, J., Brusic, V., Song, L., Qiao, Z., Wang, J. H., Wagner, G., Reinherz, E. L. Immunity 2008, 28, 52-63.

(64) Sun, Z. Y., Cheng, Y., Kim, M., Song, L., Choi, J., Kudahl, U. J., Brusic, V., Chowdhury, B., Yu, L., Seaman, M. S., Bellot, G., Shih, W. M., Wagner, G., Reinherz, E. L. J. Mol. Biol. 2014, 426, 1095-108.

Anandakrishnan, R.; Drozdetski, A.; Walker, R. C.; Onufriev, A. $V$. Speed of Conformational Change: Comparing Explicit and Implicit Solvent Molecular Dynamics Simulations. Biophysical Journal, 2015, 108, 1153-1164.

Miyamoto, S.; Kollman, P. SETTLE: An analytical version of the SHAKE and RATTLE algorithm for rigid water models. J. Comput. Chem., 1992, 13, 952-962.

xx. Sonti, R.; Gowd, K. H.; Rao, K. N. S.; Ragothama, S.;

Formatat: Tipus de lletra: (Per defecte) Arial, 8,5 pt

Formatat: Tipus de lletra: $8,5 \mathrm{pt}$ Rodriguez, A.; Perez, J. J.; Balaram, P. Chem. Eur. 2013, 19, $15175-15189$ 
Entry for the Table of Contents (Please choose one layout)

Layout 1:

\section{FULL PAPER}

Text for Table of Contents

Author(s), Corresponding Author(s)*

Page No. - Page No.

Title

((Insert TOC Graphic here: max. width: $5.5 \mathrm{~cm}$; max. height: $5.0 \mathrm{~cm})$ )

Layout 2:

\section{FULL PAPER}

((Insert TOC Graphic here; max. width: $11.5 \mathrm{~cm}$; max. height: $2.5 \mathrm{~cm}$ ))

Author(s), Corresponding Author(s)*

Page No. - Page No.

Title

Text for Table of Contents 